2 Heffernan AM, White $M$, Curran A, Colbert $S A$. Laryngeal mask airway severed by biting. Eur J Anaesthesiol 2003; 20: 74-5.

3 Quinlan J. Reinforced laryngeal mask severed by biting. Anaesthesia 2000; 55: 186.

4 Cook TM, Lee G, Nolan JP. The ProSeal laryngeal mask airway: a review of the literature. Can J Anesth 2005; 52: 739-60.

\section{Preoperative smoking cessation and smoke-free policy in a university hospital in Japan}

To the Editor:

In recent years, implementation of smoke-free policies has increased in Japanese hospitals (none in 2002, but $37 \%$ in 2006 ; survey by the Japanese Circulation Society). This shift has provided an opportunity to encourage smoking cessation amongst patients presenting for surgery, and those who are otherwise hospitalized. In our university hospital, smoking has been prohibited in all indoor areas, as well as all hospital property, since 2005 .

Smoking status affects both perioperative risk and outcome; indeed, the physiologic changes produced by abstinence from cigarettes may have clinically relevant effects on anesthetic management and perioperative outcome. ${ }^{1,2}$ We previously reported that the implementation of a smoke-free policy in a university hospital led to significant decreases in carboxyhemoglobin levels in inpatients undergoing surgery. ${ }^{3}$ However, the factors affecting compliance with smoke-free policies among preoperative smokers are not completely understood. Hence, we conducted the present study to examine both the smoking status of surgical patients, and the factors relating to preoperative abstinence from cigarettes. Ethical approval for the study protocol was obtained from the University Research Ethics Board of Gifu University.

We evaluated, at preoperative interview, 2,011 patients who were greater than eighteen years of age, scheduled for elective surgery between April 2006 and March 2007. Forty three subjects could not respond directly to the interview, due to a mental disorder or dementia, and were excluded. Anesthesiologists interviewed all patients using a standardized questionnaire that examined the following: medical history, smoking history [cessation time, reason for smoking cessation, cessation method, and employment or non-employment of nicotine replacement therapy (NRT)], awareness of the risks of perioperative smoking, intention to continue abstaining from smoking after discharge, and awareness of the smoke-free policy of the hospital. A total of 1968 patients (100\%) completed the questionnaire. Data were analyzed for 928 males $[59 \pm 18$ (18-96) yr], and 1,040 females [55 $\pm 17(18-95) \mathrm{yr}]$ and classified into five smoking categories: non-smoker, ex-smoker (at least $24 \mathrm{hr}$ abstinence from cigarettes at the time of premedication by anesthesiologist; abstinence within the two weeks before the operation $(<$ two weeks), between two weeks to three months (two weeks to three months), and three months or more (> three months), and current smokers (Table). A Chi-square test was used to compare dichotomous variables between groups.

There were 992 non-smokers (52\%), 836 ex-smokers $(41 \%)$, and 140 smokers (7\%). Only $32(4 \%)$ of the ex-smokers had used NRT. The reasons given for quitting smoking included not only doctors' advice (199 ex-smokers), but also nurses' advice (15 ex-smokers; especially useful for abstinence within the two weeks before the operation), and a hospitalization/operation (80 ex-smokers). Among the 311 ex-smokers who had quit smoking within the previous three months, 101 answered that the smoke-free hospital policy was a factor in their quitting smoking; there was a significant relationship in abstinence within the previous two weeks $(39 \%)(P=0.002$; ex-smoker $(<$ two weeks $v$ s two weeks to three months). It was more difficult to quit smoking preoperatively for female patients $(P=0.043)$ and those with benign disease $(P=0.047)$ [smoker plus ex-smoker (< two weeks) vs ex-smoker (two weeks to three months)]. An awareness of the perioperative risk of smoking was admitted by $56 \%$ of ex-smokers and $51 \%$ of smokers. However, a critical issue in this regard was that about one-half of the smokers did not have information regarding the perioperative risk of smoking. Even though preoperative abstinence was not achieved by all informants, $45 \%$ of smokers had a stated intention to stop smoking after surgery.

Mandatory smoke-free policies could contribute to some period of abstinence after surgery, and to a greater likelihood of spontaneous quitting. In addition, since nicotine withdrawal symptoms have been reported to be minimal in the postoperative period, surgery could represent an excellent opportunity for smokers to attempt sustained abstinence, to their long-term benefit. ${ }^{4}$ Even if preoperative abstinence is not achieved, postoperative abstinence would be expected to have benefits for most, if not all, surgical patients. Many of the surgical patients in the present study denied having information about the perioperative risks due to smoking, so clearly, medical staff need to be made aware of the importance of informing patients that preoperative abstinence from 
TABLE

\begin{tabular}{|c|c|c|c|c|c|c|}
\hline & & \multirow[t]{2}{*}{ Smoker } & \multicolumn{3}{|c|}{ Ex-smoker } & \multirow[t]{2}{*}{ Non-smoker } \\
\hline & & & $<2 w k$ & $2 w k-3 m o$ & $>3 m o$ & \\
\hline Number of patients & & 140 & 196 & 115 & 525 & 992 \\
\hline \multirow[t]{2}{*}{ Sex (Mean age $( \pm S D), y r)$} & Male & $\begin{array}{l}90(51 \pm 16) \\
(64 \%)\end{array}$ & $\begin{array}{l}130(56 \pm 15) \\
(66 \%)\end{array}$ & $\begin{array}{l}87(61 \pm 13) \\
(76 \%)\end{array}$ & $\begin{array}{l}434(65 \pm 13) \\
(83 \%)\end{array}$ & $\begin{array}{l}187(55 \pm 19) \\
(19 \%)\end{array}$ \\
\hline & Female & $\begin{array}{l}50(45 \pm 13) \\
(36 \%)\end{array}$ & $\begin{array}{l}66(51 \pm 16) \\
(34 \%)\end{array}$ & $\begin{array}{l}28(54 \pm 18) \\
(24 \%)\end{array}$ & $\begin{array}{l}91(54 \pm 17) \\
(17 \%)\end{array}$ & $\begin{array}{l}805(58 \pm 16) \\
(81 \%)\end{array}$ \\
\hline \multirow[t]{2}{*}{ Disease } & Benign & $95(68 \%)$ & $110(56 \%)$ & $58(50 \%)$ & $295(56 \%)$ & $609(61 \%)$ \\
\hline & Malignant & $45(32 \%)$ & $86(44 \%)$ & $57(50 \%)$ & $230(44 \%)$ & $383(39 \%)$ \\
\hline \multirow{2}{*}{$\begin{array}{l}\text { Do you know this hospital } \\
\text { is a smoke-free hospital? }\end{array}$} & Yes & $126(90 \%)$ & $168(86 \%)$ & $100(87 \%)$ & $359(68 \%)$ & $604(61 \%)$ \\
\hline & No & $14(10 \%)$ & $28(14 \%)$ & $15(13 \%)$ & $166(32 \%)$ & $388(39 \%)$ \\
\hline $\begin{array}{l}\text { Was the reason for your } \\
\text { smoking abstinence }\end{array}$ & Yes & NA & $76(39 \%)$ & $25(22 \%)$ & NA & NA \\
\hline $\begin{array}{l}\text { related to the } \\
\text { smoke-free hospital? }\end{array}$ & No & NA & $120(61 \%)$ & $90(78 \%)$ & NA & NA \\
\hline $\begin{array}{l}\text { Do you think that } \\
\text { perioperative smoking }\end{array}$ & Yes & $72(51 \%)$ & $109(56 \%)$ & $64(56 \%)$ & $193(37 \%)$ & NA \\
\hline causes complications? & No & $68(49 \%)$ & $87(44 \%)$ & $51(44 \%)$ & $332(63 \%)$ & NA \\
\hline Why did you quit smoking? & $\begin{array}{l}\text { Advice from } \\
\text { medical doctors }\end{array}$ & NA & $64(32 \%)$ & $36(31 \%)$ & $99(19 \%)$ & NA \\
\hline \multirow[t]{2}{*}{ (multiple answers allowed) } & Advice from nurses & $\mathrm{NA}$ & $12(6 \%)$ & $3(3 \%)$ & 0 & NA \\
\hline & $\begin{array}{l}\text { Hospitalization/ } \\
\text { operation }\end{array}$ & NA & $37(19 \$)$ & $10(9 \%)$ & $33(6 \%)$ & NA \\
\hline Did you use NRT & Yes & NA & $3(2 \%)$ & $10(9 \%)$ & $19(4 \%)$ & NA \\
\hline to quit smoking? & No & NA & $193(98 \%)$ & $105(91 \%)$ & $506(96 \%)$ & NA \\
\hline Do you want to quit & Yes & $63(45 \%)$ & NA & NA & NA & NA \\
\hline smoking after surgery? & No & $77(55 \%)$ & NA & NA & NA & NA \\
\hline
\end{tabular}

$\mathrm{wk}=$ weeks, $\mathrm{mo}=$ months; NRT $=$ nicotine replacement therapy. The Japanese adult smoking prevalence $(\mathrm{male}=39.3 \%$ (about $19,630,000$ ), female $=11.3 \%$ (about $6,060,000)$ ). The survey of National Health and Nutrition by the Ministry of Health, Labour and Welfare of Japan, 2005.

cigarettes may decrease perioperative complications. Furthermore, the present study suggests that even in the brief preoperative period, medical staff (including anesthesiologists, surgeons, and nurses) can, and should help patients to quit tobacco use.

Hiroki Iida MD

Mami Iida MD

Shuji Dohi MD

Naokazu Fukuoka MD

Miki Iida MD

Gifu University Graduate School of Medicine, GifuCity, Gifu, Japan

This work was supported by Grant-in Aid for Scientific Research No. 18591697 (Ministry of Education, Science and Culture, Japan).
This work was presented at the 2007 Annual Meeting of the American Society of Anesthesiologists on October 13, 2007, San Francisco.

No author has any financial interest in the subject matter, materials, or equipment discussed in this letter.

E-mail: iida@gifu-u.ac.jp Accepted for publication February 14, 2008.

\section{References}

1 Warner DO. Perioperative abstinence from cigarettes: physiologic and clinical consequences. Anesthesiology 2006; 104: 356-67.

2 Warner DO. Tobacco control for anesthesiologists. J Anesth 2007; 21: 200-11.

3 Dohi S, Iida M, Iida H, Nagase K, Nagata C. 
Implementation of smoke-free policy in university hospital decreases carboxyhemoglobin level in inpatients undergoing surgery. Anesthesiology 2007; 106: 406-7.

4 Warner DO, Sarr MG, Offord KP, Dale LC.

Anesthesiologists, general surgeons, and tobacco interventions in the perioperative period. Anesth Analg 2004; 99: 1766-73.

\section{Survival with extreme lactic acidosis following ethylene glycol poisoning?}

To the Editor:

A 47-yr-old woman, with a past history of self-poisonings associated with a bipolar disorder, was found comatose by the relatives who suspected a drug overdose. The time delay from ingestion to presentation was approximately $12 \mathrm{hr}$. The initial Glasgow coma scale was 3 and the patient's trachea was intubated on the scene. On arrival in the emergency department $(1300 \mathrm{hr})$, vital signs were as follows: heart rate, 85 beats. $\mathrm{min}^{-1}$, arterial blood pressure, $124 / 61 \mathrm{mmHg}$, and rectal temperature, $30.5^{\circ} \mathrm{C}$. The neurological examination revealed fixed and dilated pupils, and the deep tendon reflexes were either depressed or absent. Laboratory data revealed a profound metabolic acidosis with an arterial blood $\mathrm{pH}$ of 6.56 and a lactate level of $60 \mathrm{mmol} \cdot \mathrm{L}^{-1}(\mathrm{~N}<1.3)$, while bicarbonate was $4.5 \mathrm{mmol} \cdot \mathrm{L}^{-1}$ and $\mathrm{pCO}_{2} 35 \mathrm{mmHg}$ (under mechanical ventilation, with no correction for temperature). This determination had been performed on a Radiometer $\mathrm{ABL} 725^{\mathrm{TM}}$ blood gas analyzer (Radiometer A/S, Bronshoj, Denmark). Despite this remarkable hyperlactatemia, the calculated anion gap was $35.7 \mathrm{mmol} \cdot \mathrm{L}^{-1}$. Blood urea was $13.5 \mathrm{mmol} \cdot \mathrm{L}^{-1}$ and the glucose concentration was $8.1 \mathrm{mmol} \cdot \mathrm{L}^{-1}$. The estimated osmol gap was $90 \mathrm{mOsm} \cdot \mathrm{kg}^{-1}$. The serum creatinine concentration was within normal range (132 $\mu \mathrm{mol} \cdot \mathrm{L}^{-1}$ ), but the patient was oliguric from the time of admission. Central venous blood oxygen saturation remained above $65 \%$.

A toxic alcohol ingestion was suspected, and oxalate crystals were detected in the urine sample (oxaluria $184 \mathrm{mg} \cdot \mathrm{g}^{-1}$ creatinine; $\mathrm{N}<32$ ). The diagnosis of ethylene glycol (EG) poisoning was confirmed in the serum $\left(2.78 \mathrm{~g} \cdot \mathrm{L}^{-1}\right)$. No other drug was detected by the toxicological screen. Due to the severity of metabolic acidosis with oliguria despite fluid replacement, hemodialysis was started in the intensive care unit (ICU) for a total duration of eight hours, and ethanol was preferred over fomepizole as antidotal treatment. We observed some discrepancy between the rapid correction of acidemia and the persistence of high
TABLE I Biological data from the time of admission. Uncorrected lactate measurements by Radiometer ABL $725^{\mathrm{TM}}$ (corrected for $37^{\circ} \mathrm{C}$ body temperature).

\begin{tabular}{llllll}
\hline Time & $1300 \mathrm{hr}$ & $1800 \mathrm{hr}$ & $1830 \mathrm{hr}$ & $2330 \mathrm{hr}$ & $0200 \mathrm{hr}$ \\
\hline Body temperature $\left({ }^{\circ} \mathrm{C}\right)$ & 30.5 & 36.9 & 37.1 & 36.9 & 37.2 \\
$\mathrm{pH}$ & 6.56 & 7.37 & 7.39 & 7.35 & 7.38 \\
Lactate $\left(\mathrm{mmol} \cdot \mathrm{L}^{-1}\right)$ & 60 & 25 & 15 & 7.8 & 5.2 \\
$\begin{array}{l}\text { Base excess }\left(\mathrm{mmol} \cdot \mathrm{L}^{-1}\right) \\
\text { Bicarbonate }\left(\mathrm{mmol} \cdot \mathrm{L}^{-1}\right)\end{array}$ & 3 & 11 & 14 & 18 & 20 \\
$\begin{array}{l}\text { Ethylene glycol }\left(\mathrm{g} \cdot \mathrm{L}^{-1}\right) \\
\text { Ethanol }\left(\mathrm{g} \cdot \mathrm{L}^{-1}\right)\end{array}$ & 2.78 & 1.0 & 0.57 & - & - \\
$\begin{array}{l}\text { Anion gap }(16 \pm 4) \\
\left(\text { mmol } \cdot \mathrm{L}^{-1}\right)\end{array}$ & 36.2 & 32.5 & 19.9 & - & 13.2 \\
$\begin{array}{l}\text { Osmolar gap } \\
\left(\mathrm{mOsm}_{\mathrm{kgg}} \mathrm{kg}^{-1}\right)\end{array}$ & 90.0 & 37.5 & 25.5 & 19.7 & 13.9 \\
\hline
\end{tabular}

TABLE II Analyzers for which interference on lactate results have been described for both glycolic acid and glyoxylic acid (italics) or glyoxylic acid alone. ${ }^{6}$

Synchron LX 20 (Beckman Coulter)

Bayer 860 (Bayer Diagnostics)

ABL 625, 725, 825 (Radiometer)

OMNI S (Roche Diagnostics)

CCX 4 (Nova)

Chiron 865 (Bayer Diagnostics)

Rapid Lab 1265 (Siemens Diagnostics)

Architect ci 8200 (Abbott)

serum lactate values (Table I). Ethylene glycol was no longer detectable in the serum at the end of hemodialysis. The patient became fully awake $12 \mathrm{hr}$ following admission, and her trachea was extubated shortly thereafter. She did not present immediate or delayed neurological sequelae. Intermittent hemodialysis was still required after ICU discharge for a period of five weeks, but the patient ultimately recovered normal renal function.

Severe metabolic acidosis is a common feature of toxic alcohol poisoning when the patient presents with a delay from the time of ingestion. For both methanol and EG poisoning, the final prognosis is clearly related to the severity of the initial acidosis. ${ }^{1}$ However, with aggressive supportive care, adequate antidotal therapy, and extrarenal elimination techniques when indicated, complete recovery is still possible, despite extremely low $\mathrm{pH}$ values. Fomepizole is an extremely potent inhibitor of alcohol dehydrogenase, and is effective for treatment of EG poisoning, with minimal adverse effects. The main reason fomepizole is not used in many hospitals pertains to the high acquisition cost and limited availability of this drug. Maximum therapeutic benefit can be achieved by administering 